Tomanik, G.B. Observatório Abrahão de Moraes (IAG-USP): uma opção de lazer e de turismo sustentável em um cenário natural. Anais do VIII Congresso Nacional de Ecoturismo e do IV Encontro Interdisciplinar de Ecoturismo em Unidades de Conservação. Revista Brasileira de Ecoturismo, São Paulo, v.4, n.4, 2011, p. 575.

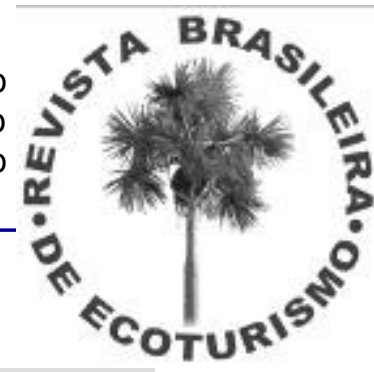

\title{
OBSERVATÓRIO ABRAHÃO DE MORAES (IAG-USP): UMA OPÇÃO DE LAZER E DE TURISMO SUSTENTÁVEL EM UM CENÁRIO NATURAL
}

\author{
Geny Brillas Tomanik* \\ *Universidade Anhembi Morumbi \\ E-mail: gbtomanik@gmail.com
}

O Observatório Abrahão de Moraes (OAM), fundado em 1972, pertencente ao Instituto de Astronomia, Geofísica e Ciências Atmosféricas (IAG) da Universidade de São Paulo (USP), localiza-se em Valinhos, porém com acesso pela vizinha Vinhedo-SP. A área de cerca de 450.000 $\mathrm{m}^{2}$ em que está inserido, composta de mata nativa, está cadastrada no IBAMA para a soltura de animais silvestres da região. A atividade principal do Observatório é direcionada à pesquisa científica, revitalizada com a implantação em 2011 do primeiro laboratório de astrobiologia no país. Além disso, a partir de 1998, o OAM tornou-se difusor de conhecimento científico, disponibilizando o espaço a visitações gratuitas ao público interessado, mediante agendamento, e apresenta um crescimento relevante, chegando a quase cinco mil visitantes entre os anos de 2009 e 2010. Essas visitações, realizadas em grupos de até 35 pessoas, são constituídas de observações in loco por meio de telescópios científicos - dependendo das condições meteorológicas - da lua e de outros objetos visíveis no céu na ocasião e de palestras ou debates, ou seja, há uma interação dinâmica, e representa uma experiência participativa e peculiar, que pode despertar o interesse pela Astronomia e fenômenos da natureza. Além disso, durante o período diurno ocorrem visitas didáticas e ocasionalmente de turistas e visitantes das Festas do Figo (Valinhos) e da Uva (Vinhedo) para conhecimento do espaço e infraestrutura de pesquisa, e "o que é" e "o que faz" um Observatório Astronômico, quando então é possível vislumbrar a rica fauna e flora local, e ainda durante o percurso entre os equipamentos é realizada a Educação Ambiental pelos monitores. Desta forma, o objetivo deste trabalho é refletir sobre o lazer e o turismo cultural, sob o viés da sustentabilidade, promovidos pelo Observatório à comunidade. Foram feitos levantamentos bibliográficos sobre lazer, turismo cultural, educação não-formal e ambiental e sustentabilidade. Como metodologia de pesquisa realizada anteriormente (2009) optou-se por entrevistas pessoais e questionários semi-estruturados realizados junto aos residentes dos municípios citados e aos visitantes no OAM, com o intuito de identificar dados referentes à caracterização do tempo livre e de lazer, as formas de lazer praticadas, além de uma avaliação sobre as visitas monitoradas, entre outros. A pesquisa de campo resultou na detecção do interesse pelo lazer cultural da população e a avaliação positiva dos respondentes sobre as visitações. Considerando-se que o meio ambiente natural e preservado do OAM já serviu de campus para estudos acadêmicos na área de biologia e devido à existência de algumas trilhas, que poderiam ser demarcadas e remanejadas, o local poderia servir ainda à atividade de Birdwatching. A preocupação ecológica e a sustentabilidade, motes da sociedade contemporânea, estendem-se hoje a todas as atividades humanas, inclusive no lazer e no turismo. Isto é o que se observa no OAM, não apenas pelo fato de preservar a mata e servir de refúgio à fauna, bem como por ser um espaço democrático à inclusão cultural/científica, e de educação não-formal, acessível a todas as classes sociais e faixas etárias, sejam autóctones ou turistas, propiciando um lazer/turismo sustentável.

Palavras-chave: Lazer e Turismo Cultural; Sustentabilidade; Observatório Abrahão de Moraes. 